ISSN: 2386-3919

ISSN electrónico: 2386-3927

DOI: http://dx.doi.org/10.14201/et20153325978

\title{
UNA APROXIMACIÓN A LA REALIDAD DE LAS PLATAFORMAS VIRTUALES DE LAS UNIVERSIDADES ESPAÑOLAS: EL PRIMER RETO PARA UNA EDUCACIÓN PERSONALIZADA EN PERSONAS CON DISCAPACIDAD MOTÓRICA O VISUAL ${ }^{1,2}$
}

\author{
An approach to the reality of the virtual learning \\ environments of Spanish universities: the first challenge \\ for a personalized education for people with motor or \\ visual disabilities
}

Un rapprochement à la réalité des plates-formes virtuelles des universités espagnoles: le premier défi pour un enseignement personnalisé pour les personnes ayant un handicap moteur ou visuel

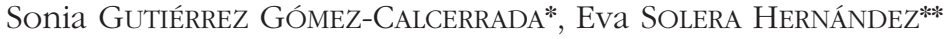 \\ y Juan Manuel GARCía GONZÁLEZ***** \\ Universidad Internacional de La Rioja \\ Gran Vía Rey Juan Carlos I, 41. 26002 Logroño, La Rioja, España \\ Correo-e: "sonia.gutierrez@unir.net; **va.solera@unir.net; ***juanmanuel.garcia@unir.net
}

1. Esta investigación ha sido financiada por el GdI-08: EDADI de UNIR Research (http://research. unir.net), Universidad Internacional de La Rioja (UNIR, http://www.unir.net), dentro del Plan Propio de Investigación, Desarrollo e Innovación [2013-2015].

2. Esta actividad forma parte del conjunto de comunicaciones del Encuentro Internacional EPEDIG de Educación Personalizada, celebrado en el mes de junio de 2014 organizado por el Grupo de Investigación GdI-07 EPEDIG-UNIR, siendo parcialmente financiada por UNIR Research (http://research. unir.net), Universidad Internacional de La Rioja (UNIR, http://www.unir.net), dentro del Plan Propio de Investigación, Desarrollo e Innovación [2013-2015]. 
UNA APROXIMACIÓN A LA REALIDAD DE LAS PLATAFORMAS VIRTUALES DE LAS UNIVERSIDADES ESPAÑOLAS: EL PRIMER RETO PARA UNA EDUCACIÓN PERSONALIZADA EN PERSONAS CON DISCAPACIDAD...

Recibido: 01-07-2014; Aceptado: 09-01-2015; Publicado: 30-10-2015

BIBLID [2386-3927 (2015) 33, 2; 59-78]

Ref. Bibl. SONIA GUTIÉRREZ GÓMEZ-CALCERRADA, EVA SOLERA HERNÁNDEZ y JUAN MANUEL GARCÍA GONZÁLEZ. Una aproximación a la realidad de las plataformas virtuales de las universidades españolas: el primer reto para una educación personalizada en personas con discapacidad motórica o visual. Enseñanza \& Teaching, 33, 2-2015, 59-78.

RESUMEN: El punto de partida para ofrecer una educación universitaria personalizada basada en entornos de educación online a personas con diversidad funcional debe centrarse en garantizar la óptima accesibilidad a su contenido web y a los recursos de aprendizaje. En la actualidad, la mayoría de las universidades disponen de plataformas virtuales de educación, con un importante peso para el correcto desarrollo de sus estudios y para la optimización del aprendizaje de su alumnado. Por otro lado, los entornos virtuales suponen un importante punto de acceso a la posible matriculación en dichas universidades del alumnado con discapacidad. Este trabajo tiene dos objetivos. El primero de ellos consiste en definir cuáles son las condiciones óptimas de accesibilidad web de las plataformas virtuales de educación y de los sitios web de las universidades para personas que presentan discapacidad visual o discapacidad motórica, de acuerdo a los estándares internacionales. El segundo objetivo del trabajo persigue ofrecer una breve aproximación al grado de accesibilidad de los sitios web de las universidades españolas para el alumnado con esas dos discapacidades. El trabajo sigue un diseño descriptivo basado en dos elementos de análisis. Por un lado, la revisión de estudios de accesibilidad y diversidad funcional y, por otro, el análisis de la accesibilidad web de los sitios web de las 78 universidades españolas. Se concluye que existen dificultades de accesibilidad web y navegación en los entornos virtuales de las universidades españolas, situación que, por lo tanto, redunda en limitaciones en el aprendizaje de los colectivos de estudiantes con limitaciones.

Palabras clave: accesibilidad web; universidad; educación personalizada; discapacidad visual; discapacidad motórica.

SUMMARY: The starting point to provide a university education-based custom environments online education to people with functional diversity must focus on ensuring the optimal accessibility to your web content and learning resources. At present, most of the universities now have virtual platforms of education, with an important weight for the correct development of their studies and for the optimization of learning of its students. On the other hand, the virtual environments pose a major access point to the possible enrolment in these university students with disabilities. This paper has two objectives. The first of them is to define which are the optimal conditions for web accessibility in the virtual platforms of education and the web sites of universities for people who have visual impairment or motor disabilities, according to international standards. The second objective of this work aims 
UNA APROXIMACIÓN A LA REALIDAD DE LAS PLATAFORMAS VIRTUALES DE LAS UNIVERSIDADES ESPAÑOLAS: EL PRIMER RETO PARA UNA EDUCACIÓN PERSONALIZADA EN PERSONAS CON DISCAPACIDAD...

to deliver a brief approximation on the degree of accessibility of the web sites of the Spanish universities for students with these two disabilities. The work follows a descriptive design based on two elements of analysis. On the one hand, the review of studies of accessibility and functional diversity; and on the other hand, the analysis of web accessibility of the web sites of the 78 Spanish universities. It is concluded that there are difficulties of web accessibility and navigation in the virtual environments of the Spanish universities, a situation that, therefore, leads to limitations in the learning from the collective of students with disabilities.

Key words: web accessibility; university; personalized education; visual disability; motor disability.

RÉSUMÉ: Le point de départ pour offrir une éducation universitaire personnalisée fondée dans des environnements de l'éducation online à personnes avec diversité fonctionnelle doit viser à assurer l'optimale accessibilité à son contenu Web et aux ressources d'apprentissage. Actuellement, la plupart des universités disposent de plates-formes virtuelles de l'éducation, avec un poids important pour le bon déroulement de leurs études et pour l'optimisation de l'apprentissage des élèves. D'autre part, les environnements virtuels représentent un important point d'accès à l'éventuelle inscription dans ces universités des élèves handicapés. Ce travail a deux objectifs. Le premier d'entre eux est à définir quels sont les conditions optimales d'accessibilité Web des plates-formes virtuels de l'éducation et des sites Web des universités de personnes qui présentent incapacité visuelle ou d'invalidité motrice, conformément aux normes internationales. Le deuxième objectif du travail poursuit offrir un bref rapprochement au degré d'accessibilité des sites Web des universités espagnoles pour les élèves avec ces deux handicaps. Le travail est une conception descriptive fondée sur deux éléments d'analyse. D'une part, la révision des études d'accessibilité et la diversité fonctionnelle; et d'autre part, l'analyse de l'accessibilité Web des sites Web des 78 universités espagnoles. Il est conclu qu'il existe des difficultés d'accessibilité Web et de la navigation dans les environnements virtuels des universités espagnoles, situation qui, par conséquent, sert limitations à l'apprentissage des collectifs d'étudiants handicapés.

Mots clés: accessibilité web; université; éducation personnalisée; handicap visuel; handicap motrice.

\section{INTRODUCCIÓN}

La Ley Orgánica 4/2007, sobre universidad y derechos de las personas con discapacidad, vela por los intereses y derechos de éstas a acceder a estudios universitarios, estableciendo cuáles son las responsabilidades de administraciones y universidades que garantizan los recursos necesarios para proporcionar una igualdad de condiciones en esta etapa educativa. Por tanto, el sistema universitario de educación superior en España debe garantizar la igualdad de acceso, de aprendizaje y de oportunidades en los estudios a cualquier persona. Sin embargo, hay estudiantes, como 

EL PRIMER RETO PARA UNA EDUCACIÓN PERSONALIZADA EN PERSONAS CON DISCAPACIDAD...

ocurre con los alumnos con discapacidad o diversidad funcional, que, más allá de sus aptitudes y capacidades, presentan dificultades para adquirir elementos educativos que les garanticen un aprendizaje óptimo a través de las plataformas virtuales de educación (Personal Learning Environments, PLE en sus siglas en inglés). Aunque el porcentaje de alumnos universitarios con discapacidad es bajo (Ministerio de Trabajo y Asuntos Sociales, 2007), teniendo en cuenta el rango de edad en el que más personas comienzan los estudios universitarios, datos recientes, sobre el curso 2013-2014, hablan de un aumento del 10\% respecto al curso anterior (Fundación Universia, 2014). No obstante, las oportunidades de acceso a estudios superiores se ven más limitadas a medida que aumenta el grado de estudio universitario. Según el segundo informe del Observatorio «Universidad y Discapacidad", elaborado por el Comité Español de Representantes de Personas con Discapacidad (CERMI) y la Fundación Universia (2014), del total de alumnado matriculado en estudios universitarios en España, los estudiantes con discapacidad representan el 1,3\% en estudios de grado, el 1,2\% en estudios de postgrado y únicamente el $0,6 \%$ en estudios de doctorado. Este mismo informe revela un dato clave relacionado con la importancia de un óptimo entorno virtual de las plataformas universitarias, y es que el 3,1\% de los alumnos matriculados en universidades a distancia presentan algún tipo de discapacidad, frente al 0,9\% en la universidad presencial.

Este trabajo pretende estudiar la relación que hay entre la accesibilidad web de las PLE y las características de las personas con diversidad funcional visual o motórica. En este sentido se plantean dos objetivos: por un lado, definir cuáles son las condiciones óptimas de accesibilidad web de las plataformas virtuales de educación y de los sitios web de las universidades para personas que presentan discapacidad visual o motórica, en función de los estándares internacionales. Y, por otro, ofrecer una breve aproximación sobre el grado de accesibilidad de los sitios web de las universidades españolas para el alumnado con esas dos discapacidades. De este modo, podremos sentar las bases para una educación personalizada de calidad del alumnado con discapacidad en entornos virtuales.

\section{DISCAPACIDAD Y DIVERSIDAD FUNCIONAL}

Para entender mejor este tema, debemos conocer la diferencia entre discapacidad y diversidad funcional. La primera está ligada a una deficiencia que impide o dificulta que la persona lleve a cabo alguna/s acción/es de una forma considerada normal para el resto de la población (OMS, 1999, 2011). La segunda hace referencia a la diferencia de capacidades entre unas personas y otras (Discapnet, s. f.).

Las personas con discapacidad o diversidad funcional recorren un complejo camino hasta llegar a matricularse en la universidad, que generalmente sigue manteniendo esquemas presenciales y virtuales de aprendizaje diseñados para estudiantes sin diversidad funcional. Para dicha matriculación, los sitios web de las universidades y la información que contienen en materia de accesibilidad web para las diversas discapacidades juegan un importante papel. 
UNA APROXIMACIÓN A LA REALIDAD DE LAS PLATAFORMAS VIRTUALES DE LAS UNIVERSIDADES ESPAÑOLAS: EL PRIMER RETO PARA UNA EDUCACIÓN PERSONALIZADA EN PERSONAS CON DISCAPACIDAD...

No obstante, desde 1996 se ha realizado un enorme esfuerzo desde diferentes organizaciones para apoyar la integración e inclusión educativa y social de los estudiantes universitarios con discapacidad con la creación de servicios y programas específicos de atención en la Universidad española (Peralta, 2010).

\section{ACCESIBILIDAD WEB: DEFINICIÓN Y NORMATIVA}

Uno de los aspectos en los que se deben centrar estos servicios universitarios debe ser el de la accesibilidad web, entendida esta como el diseño web que permite que las personas con discapacidad puedan interactuar, comprender y navegar en la web y en sus contenidos. Todas las universidades españolas utilizan PLE como apoyo docente, la gran mayoría tienen programas docentes online, e incluso algunas ofrecen una educación completamente online. Una adecuada accesibilidad a estos entornos se torna esencial para una correcta adquisición de las competencias para todos los estudiantes. En este sentido, es necesario que los contenidos de las plataformas virtuales universitarias garanticen una óptima accesibilidad web para contribuir al correcto desarrollo de los estudios en los alumnos que presentan discapacidad.

En 1999, la comunidad internacional World Wide Web Consortium (w3c) estableció una serie de recomendaciones técnicas con las que se aportaron criterios de construcción de páginas web para mejorar la accesibilidad de navegación y a los contenidos web: el estándar de las Web Contents Accesibility Guidelines 1.0 (WCAG 1.0). En 2008, este estándar internacional se sustituyó por las pautas WCAG 2.0, si bien ambas pautas coexisten. En cuanto a las páginas web de las universidades españolas, la mayoría siguen las recomendaciones de las pautas WCAG 1.0 (como veremos más adelante), una situación comprensible dada la novedad de las WCAG 2.0 y que, en principio, no debería ser un hándicap para que pudieran ofrecer una accesibilidad web óptima.

Ambas pautas son una referencia normativa técnica que explica cómo hacer que la navegación y los contenidos de las páginas web sean accesibles, especialmente para colectivos con diversidad funcional, pero en último término para todos los usuarios. Se orientan tanto a desarrolladores web como a cualquier usuario que pretenda estudiar o crear una web accesible.

En primer lugar, las pautas WCAG 1.0 especifican catorce principios generales para un diseño accesible que, a su vez, se asocian a unos puntos de verificación que se clasifican por prioridades (w3C, 1999). Dependiendo de qué puntos de verificación se cumplan, la página o el sitio web alcanzará el nivel de prioridad 1, 2 o 3. El cumplimiento de la prioridad 1 otorga un nivel de adecuación A; de las prioridades 1 y 2 un nivel de adecuación AA; y de las prioridades 1, 2 y 3 un nivel de adecuación AAA.

Posteriormente, las pautas WCAG 2.0 modernizaron las WCAG 1.0 con una filosofía basada en dos principios adaptados a la nueva realidad de la comunidad internacional World Wide Web, del diseño web y del perfil de usuario. Primero, 
una neutralidad tecnológica que permitiera que los contenidos fueran adaptables a cualquier tecnología y contexto de contenido. En segundo lugar, un soporte para la accesibilidad por parte de los productos de apoyo de los usuarios (muy importante para algunos tipos de diversidad funcional), de los navegadores o de cualquier otro tipo de tecnología asociada al acceso web. Uno de los objetivos de este soporte es equiparar las condiciones de accesibilidad de las personas con y sin diversidad funcional (w3C, 2008).

Las pautas WCAG 2.0 señalan cuatro principios que debe cumplir toda página web accesible: perceptible, operable, comprensible y robusta. El cumplimiento de los sesenta y un criterios de accesibilidad y los cinco requisitos de conformidad definidos por la comunidad w3C (2008) adecuará la página web a una accesibilidad definida en tres niveles de conformidad: A, AA y AAA. La comunidad w3C (2008) establece que la consecución de los dos últimos niveles podrá garantizar una accesibilidad web adecuada a las personas con diversidad funcional.

En España, la legislación actual de accesibilidad web se recoge en la norma UNE de la Asociación Española de Normalización y Certificación (AENOR) 139803:2012 (AENOR, 2012), que equivale a la norma ISO/IEC 40500:2012 (ISO, 2012) y al estándar internacional de las WCAG 2.0 del w3C (2012).

Por otro lado, hay dos normas que recogen los requisitos de accesibilidad y las necesidades de software y hardware para las personas con discapacidad en general y para diferentes tipos, como las visuales, las auditivas, las físicas o las psíquicas. Dicha legislación se recoge en las normas unE 139801:2003 (AENOR, 2003) (para soporte físico o hardware) y 139802:2009 (AENOR, 2009) (para soporte lógico o software y para el interfaz de usuario).

Las personas con diversidad funcional encuentran diferentes barreras de acceso a la navegación web. Por ello, en esta investigación se estudiará la accesibilidad web para las dos discapacidades más comunes en el estudiantado universitario español (Fundación Universia, 2014): visual y motórica.

\section{DisCAPACIDAD Y ACCESIBILIDAD WEB EN LA UNIVERSIDAD ESPAÑOLA}

\subsection{Discapacidad visual}

Las personas con discapacidad visual representan un 11\% de la población española con discapacidad (INE, 2008). Según el informe de la Fundación Universia y CERMi (2014) los estudiantes de grado con discapacidad visual suponen el 8,3\% del total de alumnos universitarios con discapacidad, ascendiendo al 11,4\% en estudios de posgrado y Máster; siendo el segundo tipo de discapacidad más prevalente en la Universidad española.

La versión 10 de la Clasificación Internacional de Enfermedades (CIE-10; OMS, 2014) recoge la existencia de dos tipos de discapacidad visual: baja visión (une discapacidad moderada y grave) y ceguera. Se entiende que una persona tiene discapacidad visual cuando presenta dificultades de visión en algún ojo. La tipología de 
UNA APROXIMACIÓN A LA REALIDAD DE LAS PLATAFORMAS VIRTUALES DE LAS UNIVERSIDADES ESPAÑOLAS: EL PRIMER RETO PARA UNA EDUCACIÓN PERSONALIZADA EN PERSONAS CON DISCAPACIDAD...

discapacidad visual es muy variada y se puede definir en términos legales, sociales y oftalmológicos. En este trabajo se opta por una tipología médica dicotómica: resto visual y ceguera total. Las personas con resto visual responden a estímulos visuales y conservan algún resto visual funcional para actividades de la vida diaria, como la movilidad, las tareas domésticas o la lectura. Las personas con ceguera total no tienen resto visual o no es funcional (Junta de Andalucía, 2001; OMS, 2014). Según datos de afiliación de la Organización Nacional de Ciegos Españoles (ONCE) (2013), se distribuyen en un $81 \%$ y un $19 \%$, respectivamente.

Esta distinción es esencial en términos de capacidad de accesibilidad web y de adquisición de contenidos de aprendizaje, ya que las personas con ceguera total tienen un punto de partida sin dos elementos que poseen las personas con resto visual: las experiencias visuales previas y la funcionalidad del resto visual. Por ejemplo, Porras y Ribera (2008) encontraron diferencias de accesibilidad y usabilidad entre ambos grupos en diversos criterios WCAG 1.0, con sorprendentes mejores resultados para las personas ciegas en eficacia y eficiencia en la ejecución de tareas. En general, las personas ciegas tienen mayor satisfacción en la accesibilidad web que las personas con resto visual o sin discapacidad visual, debido a que estas presentan un menor umbral de frustración a la hora de la navegación web y un mayor uso de las facilidades de accesibilidad que ofrecen las webs (Lazar, Allen, Kleiman y Malarkey, 2007; Porras y Ribera, 2008; Theofanos y Redish, 2003).

La diferenciación de tipología de discapacidad visual se torna aún más relevante a la hora de hacer orientaciones para la mejora de la accesibilidad web, con tres factores diferenciales que la recomiendan (Álvarez, 2011): el proceso y el momento de pérdida de la visión; el grado de funcionalidad del resto visual; las diferentes patologías y condiciones del entorno. Por ello, se hace pertinente la distinción entre personas ciegas y personas con resto visual, tanto para ofrecer orientaciones de desarrollo web como para desarrollar recursos técnicos, de software y de hardware que les faciliten la accesibilidad web.

En el mundo universitario, los entornos PLE necesitan de una accesibilidad plena para que los estudiantes con discapacidad visual puedan acceder a todos los contenidos y navegar por el PLE en igualdad de condiciones que los estudiantes sin discapacidad. Por ello, es necesario proporcionar dos cosas al estudiante con discapacidad visual: una PLE con accesibilidad y usabilidad óptimas y unos recursos adaptativos de apoyo.

En el primer caso, se pide a todas las universidades y a los desarrolladores web de plE que adopten los criterios de accesibilidad web que proponen las normativas citadas en el menor plazo posible, normas de aplicación a todos los efectos pero sin plazos definidos. Esto redundará en beneficio para todos los estudiantes, independientemente de su discapacidad o aptitudes. Con este fin, el Center for Persons with Disabilities (Webaim, 2014) de Estados Unidos propone adaptaciones para mejorar la accesibilidad web tanto para personas ciegas como con resto visual.

Para ambas se proponen soluciones que optimizan los contenidos y las herramientas de navegación de la web, de modo que se eliminan colores, botones e 

EL PRIMER RETO PARA UNA EDUCACIÓN PERSONALIZADA EN PERSONAS CON DISCAPACIDAD...

imágenes inservibles o que solo se interpretan visualmente; se clarifican y se da destino real a los enlaces; se facilita el acceso mediante teclado; se minimiza el uso del ratón; se aportan descripciones auditivas; y se fomentan los lectores de pantalla basados en css.

Exclusivamente para las personas con resto visual, se recomienda que se reduzca el total del desplazamiento horizontal para facilitar la accesibilidad a los usuarios que utilizan ampliadores de pantalla; que se limite o elimine el texto dentro de los gráficos; y que se use antialiasing para hacer el texto más legible.

Para el segundo caso, hay diferentes recursos para facilitar la accesibilidad, la usabilidad y el acceso a los contenidos de las web en general, y de las PLE en particular.

Desde la ONCE, Álvarez (2011) distingue dos campos de actuación para cada tipo de discapacidad visual. Para los estudiantes sin resto visual propone dos recursos. Primero, adaptaciones sonoras: grabaciones digitales de material bibliográfico en formato Daisy, uso del sistema AUDESC de audiodescripción y explicaciones orales de personas de apoyo. Y segundo, herramientas de acceso al ordenador: el lector de pantalla JAws; escáneres con el sistema de reconocimiento de caracteres OCR, que permite el acceso a textos impresos no digitalizados; y teclados adaptados.

Por otro lado, algunos autores han propuesto agentes inteligentes para facilitar la accesibilidad web a los discapacitados visuales, aunque algunas aún no son compatibles con las directrices WCAG 2.0; Zhu, Sato, Takagi y Asakaba (2010) presentan el agente de voz Sasayaki, que aumenta la salida de voz principal por un canal secundario. Este agente hace un seguimiento de uso de navegación y acceso, de modo que disminuye los tiempos de búsqueda y aumenta la confianza del usuario. En esta misma línea, Chen, Harper, Lunn y Brown (2013) proponen un agente de identificador de contenido web dinámico y de widgets.

Otros investigadores presentan enfoques adaptados a las WCAG 2.0. Por ejemplo, Puzis (2012) plantea un enfoque que incorpora un filtrado de información y una redirección al usuario a los contenidos más relevantes de la página, aumentando así su confianza y disminuyendo su carga cognitiva. Garrido, Firmenich, Rossi, Grigera, Medina-Medina y Harari (2013) formulan la Client-Side Web Refactoring (CWRS), que permite crear vistas personalizadas que mejoran la navegación, la accesibilidad y la estructura de navegación sin pérdida de funcionalidad. Finalmente, el método de Vigo y Harper (2013) es una aplicación que evalúa automáticamente la accesibilidad de los sitios web.

En segundo lugar, Álvarez (2011) indica que para los estudiantes con resto visual se debe hacer un diagnóstico previo de su discapacidad visual, porque las múltiples situaciones que se pueden dar condicionan sus necesidades educativas. De forma breve, lo principal es saber qué ve, cómo ve y cuál va a ser la evolución de su discapacidad. En todo caso, da dos consideraciones generales para aquellos estudiantes que presentan discapacidad visual grave. Primero, la lectoescritura en tinta, de modo que se maximice el resto visual que conservan para acceder a la información, bien mediante ese resto, bien mediante una lupa que pueda modificar 
UNA APROXIMACIÓN A LA REALIDAD DE LAS PLATAFORMAS VIRTUALES DE LAS UNIVERSIDADES ESPAÑOLAS: EL PRIMER RETO PARA UNA EDUCACIÓN PERSONALIZADA EN PERSONAS CON DISCAPACIDAD...

el tamaño y visualización de los textos en términos de contraste, intensidad y resolución. Segundo, promocionar el acceso a recursos didácticos visuales diferentes a los habituales: programa Zoomtext o magnificadores de pantalla que combinen la lectura visual con la adaptación sonora.

En resumen, según Loy y Batiste (1998) se debe insistir en la accesibilidad web en las PLE en la interacción entre tres elementos:

1. Accesibilidad al ordenador: ayudas técnicas en hardware y software, distinguiendo entre personas ciegas y con resto visual.

2. Accesibilidad del navegador: adaptar los existentes o desarrollar alguno específico para personas con discapacidad visual.

3. Accesibilidad del diseño de las páginas web: mejoras en el contenido y estructuración del sitio web y de las páginas que lo conforman.

Tal y como indicaba Rodríguez (2000), es necesario apostar por un diseño que incorpore elementos de accesibilidad web que haga que los entornos sean accesibles para todos, independientemente del grado de discapacidad visual o de otro tipo que se tenga. Más recientemente, Serrano y Palomares (2013) concluyen que las PLE y los recursos de aprendizaje deben ser accesibles en sus aspectos técnicos y, más importante, en los didácticos. De este modo, el estudiante con discapacidad visual podrá compartir y aprender en igualdad de condiciones, favoreciendo la educación inclusiva y haciéndole partícipe de la diversidad de la clase. Para ello, la comunidad docente e informática deben trabajar en estrecha relación para que todos los alumnos se beneficien de PLE accesibles para todos.

\subsection{Discapacidad motórica}

La Encuesta de Discapacidad, Autonomía personal y situaciones de Dependencia (EDAD; INE, 2008) señala que la motórica es el principal tipo de discapacidad en España, afectando a 1,5 millones de personas en lo que respecta a articulaciones y huesos; aunque también pueden verse afectados nervios y músculos (Díaz, 2010).

Por tanto, la discapacidad motórica supone la alteración de la movilidad de una o algunas partes del cuerpo, y esto conlleva una alteración importante a la hora de llevar a cabo las Actividades Básicas de la Vida Diaria (ABVD).

Según datos del informe de la Fundación Universia y CERMI (2014), los alumnos de grado con discapacidad física suponen el 51,8\% del total de alumnado discapacitado, y el 46\% para el caso de alumnos de Máster y posgrado. Aunque es importante destacar que en dichos porcentajes se incluye también discapacidad orgánica, por lo que no es posible ofrecer un dato exacto sobre discapacidad motórica; no obstante, se estima que es el tipo de discapacidad más prevalente.

Como señala F3 Tics S.L.U. (s. f.), cuando las personas con este problema acceden a una página web pueden encontrarse con algunas barreras: elementos pequeños difíciles de utilizar por falta de precisión, problemas al utilizar el dispositivo con teclado o ratón o tiempos reducidos al manejar la página. 
Por tanto, presentar una discapacidad motórica conlleva dificultades de mayor o menor grado a la hora de manejarse tanto en entornos educativos convencionales como virtuales. Por este motivo, las universidades deben intentar proporcionar a los estudiantes con estos problemas herramientas y recursos que faciliten su aprendizaje (León y Bengochea, 2013).

Con este objetivo se han creado PLE y ayudas tecnológicas específicas, como las planteadas por León y Bengochea (2013):

- Teclados con teclas de tamaño diferente al habitual, con diferente distribución o con teclas especiales.

- Pulsadores que se activan con una boquilla o con movimientos manuales para sustituir al ratón y el teclado.

- Trackballs, para personas con dificultad manual, y joysticks, manejados con los pies, la barbilla, etc.

- Señaladores o licornios para manejar el teclado o la pantalla táctil usando la cabeza o en la barbilla.

- Sistemas de reconocimiento de voz para manejar el ordenador o para escribir.

- Sistemas de reconocimiento facial utilizados para manejar el ordenador.

- A todo lo anterior F3 Tics S.L.U. (s. f.) añade los ratones especiales y los sistemas de seguimiento de ojos.

Aparte de esto, León y Bengochea (2013) plantean la necesidad de ofrecer una formación virtual a los alumnos para que sepan manejar correctamente la página web de la universidad.

En esta misma línea, a través de la colaboración entre el Centro de Educación Especial Alborada y el Centro Politécnico Superior de la Universidad de Zaragoza (Martínez et al., 2007), se han desarrollado las siguientes ayudas técnicas para favorecer la accesibilidad web de las personas con discapacidad motórica:

- Ratón virtual. A diferencia del ratón tradicional se maneja con el teclado, un pulsador o un micrófono.

- Sistema de guiado de una silla robotizada a través de voz o de pantalla táctil. La silla dispone de unos sensores para obtener información del entorno y facilitar el movimiento.

Aparte de estos recursos, están en proyecto de desarrollo el programa de guiado y localización para el desarrollo de la autonomía personal, el acelerómetro para la discriminación de los movimientos voluntarios en personas con la motricidad comprometida y las herramientas de control de entorno, entre otros.

Por otro lado, Alcantud, Guarinos y Roig (2011) consideran que al hablar de accesibilidad web hay que tener en cuenta varios aspectos: construcción de la web, navegadores utilizados y sistemas de apoyo.

Si nos centramos en los sistemas de acceso, estos investigadores plantean que todos los recursos y herramientas mencionados anteriormente pueden clasificarse en dos grupos: 
UNA APROXIMACIÓN A LA REALIDAD DE LAS PLATAFORMAS VIRTUALES DE LAS UNIVERSIDADES ESPAÑOLAS: EL PRIMER RETO PARA UNA EDUCACIÓN PERSONALIZADA EN PERSONAS CON DISCAPACIDAD...

- Sistemas de entrada de selección directa. Se basan en la rapidez de elección. Aquí se incluyen ayudas al teclado convencional, teclados alternativos (con teclas más pequeñas o de colores; planos y sensibles al tacto; más pequeños; otros que se manejan con una sola mano, con pedales), emuladores de ratón (joysticks o trackball; ratones PAD; pantallas táctiles y tabletas, movimientos de cabeza recogidos con una diadema; uso de webcam por contraste de color; seguimiento de la pupila; utilización de electromiograma o electroencefalograma, y teclados virtuales).

- Sistemas de entrada por barrido o asistido. En este caso no es necesario que el usuario sea tan preciso y se reduce el tiempo de respuesta. Dentro de este grupo encontramos pulsadores clasificados según cómo se realice su activación (presión; posición; contacto, sensibilidad o de flexión; de palanca; pedal; de soplo-de succión; neumático; por sonido o vibración; por luz; acción compleja) y según la parte del cuerpo que hay que utilizar para activarlo.

En relación con lo anterior, se ha desarrollado una herramienta novedosa para facilitar la utilización de ordenadores por parte de las personas con déficits motóricos: EnPathia. Con ella es posible manejar el teclado y el ratón a través de movimientos de diversas partes del cuerpo como la cabeza, la pierna o la muñeca (Universidad de Málaga, 2012).

Todos estos recursos y herramientas, sin duda, facilitan el acceso de los estudiantes a los contenidos web, pero es fundamental que las universidades sigan los puntos establecidos por Loy y Batiste (1998): accesibilidad al ordenador, del navegador y del diseño de las páginas web.

Todas las medidas adoptadas para mejorar la accesibilidad deben enmarcarse dentro de las directrices WCAG 2.0. Por tanto, Miró y Bernabeu (s. f.) señalan que aún no se atienden adecuadamente las necesidades de las personas con discapacidad motórica, puesto que no se tienen en cuenta las dificultades de control que presenta este colectivo ni el tiempo de respuesta. En este sentido, tal y como planteamos al hablar de discapacidad visual, se detecta la necesidad de que a nivel educativo y de diseño web se aúnen esfuerzos para conseguir la accesibilidad de todos los alumnos.

\section{UNA BREVE REVISIÓN DE LA ACCESIBILIDAD WEB EN LA UNIVERSIDAD ESPAÑOLA}

\subsection{Material y metodología}

Para conocer la situación actual de accesibilidad web en las universidades españolas se ha hecho una revisión somera de la accesibilidad de sus sitios web.

La muestra del estudio está constituida por 78 universidades: 50 públicas y 28 privadas. En cuanto a la modalidad de estudio, hay 6 universidades a distancia u online, de las que 5 son privadas y el resto son presenciales. Del sitio web de 

EL PRIMER RETO PARA UNA EDUCACIÓN PERSONALIZADA EN PERSONAS CON DISCAPACIDAD...

cada universidad, el análisis se ha centrado en la portada o página principal, que es la puerta de entrada al resto de páginas y puente de acceso a la matriculación del alumnado con diversidad funcional. Adicionalmente, se han analizado las sedes electrónicas y otras páginas web del sitio para contrastar los resultados.

Se han usado tres herramientas para el análisis de la accesibilidad web.

En primer lugar, para el estudio de los niveles y las pautas de accesibilidad, se han utilizado dos herramientas automáticas. Por un lado, la herramienta TAW Online, desarrollada por la Fundación Centro Tecnológico de la Información y la Comunicación (СТIC), que permite la verificación de normas WCAG 1.0 y 2.0 eligiendo el nivel máximo de accesibilidad: A, AA o AAA. Con ella se realizó el análisis para los dos primeros niveles en cada norma WCAG. Por otro lado, la herramienta HERA, desarrollada por la Fundación del Seminario Iberoamericano sobre Discapacidad y Accesibilidad en la Red (SIDAR), que solo permite verificar la norma WCAG 1.0. Dado que el análisis automático precisa a su vez de un análisis manual, se ha optado por un planteamiento conservador pero optimista. Conservador, porque solo se toma como nivel máximo aquel en el que no da ningún tipo de error; y optimista, porque se considera el nivel máximo que podrían alcanzar aunque el análisis automático indique que se tengan que hacer comprobaciones automáticas.

En segundo lugar, para verificar las hojas de estilo en cascada (CSS) y los documentos (x)HTML con hojas de estilo, se ha usado el validador del w3C.

En cada herramienta se introdujo la URL de la página principal de cada universidad y, en algunos casos, de otras páginas web. Este análisis automático se realizó durante el mes de octubre de 2014. Adicionalmente, y en algunos casos puntuales, se llevó a cabo una revisión manual de la accesibilidad web.

\subsection{Resultados}

En cada una de estas 78 universidades estudiamos cinco elementos: pestaña de accesibilidad en la portada del sitio web de la universidad, web específica de accesibilidad, símbolos de accesibilidad de los estándares WCAG, información sobre la normativa nacional e internacional sobre accesibilidad y guía específica de accesibilidad (Tabla 1). 
UNA APROXIMACIÓN A LA REALIDAD DE LAS PLATAFORMAS VIRTUALES DE LAS UNIVERSIDADES ESPAÑOLAS: EL PRIMER RETO PARA UNA EDUCACIÓN PERSONALIZADA EN PERSONAS CON DISCAPACIDAD...

TABLA 1

Información sobre accesibilidad web en el sitio web de las universidades españolas. Número de universidades

\begin{tabular}{|l|c|c|}
\hline & Sí & No \\
\hline Pestaña de accesibilidad en portada & 38 & 40 \\
\hline Web específica de accesibilidad & 48 & 30 \\
\hline Símbolos de estándares WcaG & 16 & 62 \\
\hline Información sobre normativa & 26 & 52 \\
\hline Guía específica de accesibilidad & 12 & 66 \\
\hline
\end{tabular}

Primero, vemos que más de la mitad de las universidades estudiadas no tienen una pestaña de accesibilidad en su portada. Sin embargo, un 61,5\% (48) sí alberga una web específica para describir la accesibilidad de sus páginas. Asimismo, solo el 20,5\% (16) ponen los símbolos que la w3C aconseja incluir para conocer los niveles de accesibilidad, y un tercio aporta información sobre la normativa de accesibilidad existente en España y a nivel internacional. Además, solo el 15,4\% (12) de las universidades tienen una guía específica sobre la accesibilidad de sus páginas web. Por lo tanto, la información que dan las universidades españolas sobre sus niveles de accesibilidad es muy limitada y, en ocasiones, errónea o anticuada. De hecho, el 20,5\% (17) de las universidades tienen un nivel de accesibilidad menor del que indican en su web, cifra que se corresponde con el 35\% de las que tienen una web específica.

Estos datos ofrecen un panorama que muestra poca transparencia por parte de las universidades a la hora de especificar sus niveles de accesibilidad web y las posibilidades reales de navegación accesible para las personas con algún tipo de diversidad funcional. El análisis de la información sobre accesibilidad que dan los sitios webs y el análisis automático de las portadas web de las universidades muestra una situación similar (Tabla 2). 
UNA APROXIMACIÓN A LA REALIDAD DE LAS PLATAFORMAS VIRTUALES DE LAS UNIVERSIDADES ESPAÑOLAS: EL PRIMER RETO PARA UNA EDUCACIÓN PERSONALIZADA EN PERSONAS CON DISCAPACIDAD...

\section{TABLA 2}

Análisis automático de accesibilidad web y de cumplimiento de estándares del w3C de las portadas de los sitios web de las universidades españolas.

Número de universidades

\begin{tabular}{|c|c|c|c|c|}
\hline Nivel de accesibilidad informado en el sitio web & A & AA & AAA & No informa \\
\hline $\begin{array}{c}\text { Nivel de accesibilidad máximo que podrían } \\
\text { alcanzar (según análisis automático) }\end{array}$ & 1 & 33 & 5 & 39 \\
\hline Normativa WCAG & 35 & 3 & 0 & 40 \\
\hline & 1.0 & 2.0 & $\begin{array}{c}\text { No } \\
\text { informa }\end{array}$ & \\
\hline HTML válido & 42 & 3 & 33 & \\
\hline & Sí & No & & \\
\hline & 28 & 50 & & \\
\hline Hojas de estilo con CSS válido & Sí & No & & \\
\hline & 32 & 46 & & \\
\hline
\end{tabular}

Primero, la mitad de las universidades no dan ninguna información sobre el nivel máximo de accesibilidad que alcanzan según las normas WCAG. De la otra mitad, una indica que cumple los requisitos para alcanzar el nivel A de la norma WCAG 1.0, 33 el nivel AA (31 de la WCAG 1.0 y 2 de la WCAG 2.0) y 5 el nivel AAA de la norma WCAG 1.0. Anotemos que, de entrada, ya solo el 50\% de las universidades españolas no dan información alguna sobre sus estándares de accesibilidad web.

Para comprobar la fiabilidad de esa información, se hace un análisis automático adoptando la postura más optimista de posible cumplimiento del nivel máximo de accesibilidad que podrían adquirir según la norma WCAG 1.0, más asequible. Así, el 51,3\% (40) de las universidades no cumple al menos un requisito de la prioridad 1 , de modo que no podrían llegar a alcanzar ninguno de los niveles. De las restantes, el 45\% (35) solo podrían llegar al nivel A, ya que incumplen alguno de los requisitos de prioridad 2; el 4\% (3) solo podrían llegar al nivel AA; y ninguna podría llegar al nivel AAA. Este somero análisis automático incide en esos bajos niveles de accesibilidad que, además, presentan divergencias con la información proporcionada en sus propias páginas web sobre accesibilidad.

Para complementar esas disparidades, comprobamos que de las que 39 que no tienen información, 23 no pueden llegar a ningún nivel de conformidad, 15 solo podrían llegar al nivel A y una podría alcanzar al nivel AA. Por su parte, aquella universidad que informaba de un nivel A, no lo cumple. De las 33 que informan sobre un nivel AA, solo dos podrían alcanzarlo, mientras que 17 podrían alcanzar el nivel A y 14 no podrían obtener ninguno. Por último, de las 5 que indicaban un nivel AAA, 3 podrían conseguir el nivel A y las otras dos ninguno. 
UNA APROXIMACIÓN A LA REALIDAD DE LAS PLATAFORMAS VIRTUALES DE LAS UNIVERSIDADES ESPAÑOLAS: EL PRIMER RETO PARA UNA EDUCACIÓN PERSONALIZADA EN PERSONAS CON DISCAPACIDAD...

Hay, por lo tanto, divergencias entre la información proporcionada y la realidad de la accesibilidad web. Esto puede deberse a dos razones: o bien la información de la web está anticuada, ya sea por un cambio de diseño o por el alto volumen de páginas que forman el sitio; o bien hay un intento de mostrar una realidad de accesibilidad y educación inclusiva que no existe.

También hemos analizado la presencia de cinco herramientas de accesibilidad web que suelen ser muy útiles para personas con discapacidad visual y motórica: atajos de teclado, navegación por voz, versión pasarela, texto alternativo en enlaces e imágenes y soporte técnico o email de contacto para problemas con la accesibilidad del sitio (Tabla 3).

\section{TABLA 3}

Herramientas para una navegación web accesible y soporte aportado de los sitios web de las universidades españolas. Número de universidades

\begin{tabular}{|c|c|c|}
\hline & Sí & No \\
\hline Atajos de teclado & 23 & 55 \\
\hline Navegación por voz & 3 & 75 \\
\hline Web pasarela & 1 & 77 \\
\hline Texto alternativo en enlaces e imágenes & $30(6$ parcial $)$ & 48 \\
\hline Soporte técnico o contacto & 28 & 50 \\
\hline
\end{tabular}

Primero, un 29,5\% (23) de las universidades facilitan atajos de teclado para navegar por su sitio web. Segundo, solo un 4\% (3) permite que se navegue mediante la interacción por voz. Tercero, solo la Universidad de Granada tiene una versión accesible de su web para personas con discapacidad. Cuarto, un 31\% (24) aporta textos alternativos a los enlaces e imágenes de sus páginas web y un $7,7 \%$ (6) lo hace parcialmente. Y, quinto, un 36\% (28) da la posibilidad de contactar vía email o vía formulario para que los estudiantes puedan expresar sus dificultades con la accesibilidad web. Estos cuatro datos inciden de nuevo en el bajo nivel de accesibilidad web de las universidades españolas.

Este somero análisis de la accesibilidad web de la Universidad española muestra básicamente dos realidades. Primero, que existen dificultades de navegación y de accesibilidad en las universidades españolas. Segundo, que la atención web a las personas con diversidad funcional no está siendo la adecuada. Hay, por lo tanto, muchas posibilidades de mejora.

\section{DisCusión}

Todos estos resultados se ven refrendados por numerosas investigaciones anteriores que destacan numerosos errores que han impedido en los últimos años 
una navegación y accesibilidad web óptimas a las personas con diversidad funcional (Ribera, Térmens y Frías, 2009; Rocha, Cobo y Alonso, 2011; Rodríguez, Viera y Castillo, 2006; Térmens, Ribera y Sulé, 2003; Toledo, 2001).

Para no padecer la rápida anacronía que se deriva de los estudios de accesibilidad a sitios web, destacamos dos trabajos muy recientes que llegan a las mismas conclusiones que el presente trabajo. Por un lado, el estudio de Hilera et al. (2013), que analiza siete universidades incluidas en los rankings universitarios internacionales y concluye que esas universidades, a pesar de situarse internacionalmente en posiciones académicas privilegiadas de rendimiento y prestigio académicos, no disponen de sitios web con un nivel de cumplimiento de accesibilidad aceptable y acorde a su reputación. Por otro, la investigación de Chacón-Medina, ChacónLópez, López-Justicia y Fernández-Jiménez (2013) incluye la novedad del análisis del cumplimiento de la norma WCAG 2.0; no obstante, sus resultados apuntan en la misma dirección. Tras la revisión de la accesibilidad web de 74 universidades españolas, mediante el análisis automático y manual de los cuatro principios y las doce pautas de verificación de la norma WCAG 2.0, este equipo constata que ninguna de las universidades analizadas cumple por completo los requisitos de accesibilidad de la norma WCAG 2.0. Esto se observa en el rango de cumplimiento en su página principal, que oscila entre el 65,79\% en la Universidad de Granada y el 36,84\% en la Universidad Pontificia de Salamanca (Chacón-Medina et al., 2013). Es más, el estudio realizado por el Grupo Hum-845 de la Universidad de Granada (Román, Bernier y Rojas, 2013) señala que ninguna universidad española cumple todos los requisitos de accesibilidad para alcanzar el nivel AAA de las 2.0. Este resultado es coherente, ya que la propia w3C (2008) recomienda no exigirlo dada la dificultad en conseguir superar algunos de los criterios de conformidad que se explicitan.

\section{CONCLUSIONES}

Para ofrecer y garantizar una educación personalizada en entornos online a personas con discapacidad, es necesario asegurar una óptima accesibilidad de la navegación y a los contenidos web de las PLE. El primer objetivo de este trabajo era definir cuáles son las condiciones óptimas de accesibilidad web de las plataformas virtuales de educación y de los sitios web de las universidades para personas que presentan discapacidad visual o discapacidad motórica, de acuerdo a los estándares internacionales. Se ha podido comprobar que existen gran cantidad de fuentes desde diversos ámbitos que informan sobre los recursos y ayudas técnicas a estudiantes con discapacidad, y que se trata de un tema, a priori, de gran importancia para los entornos educativos universitarios.

El segundo objetivo planteado por el trabajo era ofrecer una breve aproximación al grado de accesibilidad de los sitios web de 78 universidades españolas para el alumnado con esas dos discapacidades. Quedan patentes dos hechos. Primero, que muchas de las universidades no ofrecen información sobre el nivel de accesibilidad ni de sus páginas web ni de sus plataformas virtuales. Y segundo, que 
aquellas que lo hacen, reportan un mayor nivel de accesibilidad que el máximo que pueden alcanzar según el análisis automático básico. Además, casi ninguna de las universidades sigue aún las normas WCAG 2.0 en el desarrollo de sus páginas web. Por lo tanto, se presentan indicios de que las universidades españolas no ofrecen una accesibilidad web acorde con los mínimos exigidos por las normas WCAG para alumnos con discapacidad visual o motórica y, por extensión, con cualquier otro tipo de discapacidad. Aunque las universidades analizadas parecen estar preocupadas por esta cuestión, la gran mayoría de ellas no actualiza sus sitios web para adecuar las directrices y principios de las WCAG 2.0, más exigentes y adecuados a las dificultades que tienen los estudiantes con esos dos tipos discapacidades.

En conclusión, las universidades que apuesten por una educación de calidad y personalizada que se centren en las necesidades educativas de las personas con discapacidad en general, y la visual y motórica en particular, deben tener como reto prioritario garantizar una accesibilidad web adecuada a las normas WCAG 2.0 y a la Norma UNE 139803:2012. Esto tendría dos ventajas: primero, beneficiaría no solo a los estudiantes con discapacidad, sino a toda la comunidad universitaria; y segundo, se podría asegurar una igualdad de oportunidades y de acceso a los recursos de aprendizaje que ofrecen tanto el sitio web de las universidades como sus PLE, principio básico de la educación superior en España.

\section{REFERENCIAS BIBLIOGRÁFICAS}

AENOR (2003). Norma UNE 139801:2003. Aplicaciones informáticas para personas con discapacidad. Requisitos de accesibilidad al ordenador. Hardware. Recuperado el 15 de mayo de 2014. http://www.aenor.es/aenor/normas/normas/fichanorma.asp?tipoN\&codigo-N0043547\&PDF-Si\#.U3TM6cc1SIN.

AENOR (2009). Norma UNE 139802:2009. Requisitos de accesibilidad del software. Recuperado el 15 de mayo de 2014. http://www.aenor.es/aenor/normas/normas/fichanorma. asp?tipo-N\&codigo-N0043547\&PDF-Si\#.U3TM6cc1SIN.

AENOR (2012). Norma UNE 139803: 2012. Requisitos de accesibilidad para contenidos en la Web. Recuperado el 18 de octubre de 2014. http://www.aenor.es/aenor/normas/normas/fichanorma.asp?tipo-N\&codigo-N0049614.

Alcantatud, F.; Guarinos, I. y Roig, R. (2011). Inventario y descripción de las soluciones de accesibilidad a la web existentes para personas con discapacidad Física y Sensorial. Alcoy: Marfil. Recuperado el 12 de mayo de 2014. http://www.edutic.ua.es/wp-content/uploads/2012/11/inventario_soluciones.pdf.

Álvarez, F. (2011, mayo). Respuesta de la universidad a los estudiantes con discapacidad visual. Comunicación presentada en Jornadas: Inclusión de los estudiantes con discapacidad en la Universidad. Necesidades y demandas. Madrid, España. Recuperado el 15 de mayo de 2014. http://portal.uned.es/pls/portal/url/ITEM/BC22C875F4C985B2E0 40660A33700D20.

Chacón-Medina, A.; Chacón-López, H.; López-Justicia, M. D. y Fernández-Jiménez, C. (2013). Dificultades en la Accesibilidad Web de las Universidades Españolas de acuerdo a la Norma WCAG 2.0. Revista Española de Documentación Científica, 36 (4). 
UNA APROXIMACIÓN A LA REALIDAD DE LAS PLATAFORMAS VIRTUALES DE LAS UNIVERSIDADES ESPAÑOLAS: EL PRIMER RETO PARA UNA EDUCACIÓN PERSONALIZADA EN PERSONAS CON DISCAPACIDAD...

Chen, A. Q.; Harper, S.; Lunn, D. y Brown, A. (2013). Widget Identification: A High-Level Approach to Accessibility. World Wide Web, 16 (1), 1-17. http://dx.doi.org/10.1007/s11280-012-0156-6

Díaz, A. (2010). Discapacidad motora. Innovación y Experiencias Educativas, 28. Recuperado el 9 de octubre. http://www.csi-csif.es/andalucia/modules/mod_ense/revista/pdf/ Numero_28/ALVARO_DIAZ_2.pdf.

Discapnet (s. f.). Diversidad funcional. Recuperado el 12 de octubre. http://www.discapnet.es/Castellano/areastematicas/tecnologia/TecnologiaYNecesidadesHumanas/DiversidadFuncional/Paginas/default.aspx.

Fundación Universia (2014). II Estudio sobre el grado de inclusión del Sistema universitario español respecto a la realidad de la discapacidad. Fundación Universia y CERMI.

F3 Tics S.L.U. (s. f.). Tipos de discapacidad que afectan a la accesibilidad Web. Recuperado el 12 de mayo de 2014. http://www.f-3.net/deInteresDetalle.asp?id-79.

Garrido, A.; Firmenich, S.; Rossi, G.; Grigera, J.; Medina-Medina, N. y Harari, I. (2013). Personalized Web Accessibility Using Client-Side Refactoring. Internet Compunting, 17 (4), 58-66. http://dx.doi.org/10.1109/MIC.2012.143

Hilera, J. R.; Fernández, L.; Suarez, E. y Villar, T. (2013). Evaluación de la accesibilidad de páginas web de universidades españolas y extranjeras incluidas en rankings universitarios internacionales. Revista Española de Documentación Científica, 36 (1). Recuperado el 15 de mayo de 2014. http://redc.revistas.csic.es/index.php/redc/article/ viewArticle/774/909.

INE (2008). Encuesta sobre Discapacidades, Autonomía personal y situaciones de Dependencia (EDAD). Madrid: INE. Recuperado el 12 de octubre. http://www.ine.es/prensa/ np524.pdf.

ISO (2012). ISO/IEC 40500:2012. Information technology - W3C Web Content Accessibility Guidelines (WCAG) 2.0. Recuperado el 15 de mayo de 2015. http://www.iso.org/iso/ iso_catalogue/catalogue_tc/catalogue_detail.htm?csnumber-58625.

Junta de Andalucía (2001). Guía para la atención educativa a los alumnos y alumnas con déficit visual. Sevilla: Junta de Andalucía.

Lazar, J.; Allen, A.; Kleiman, J. y Malarkey, C. (2007). What frustrates screen reader users on the web: a study of 100 blind users. International Journal of Human-Computer Interaction, 22 (3), 247-269.

http://dx.doi.org/10.1080/10447310709336964

León, O. y Bengochea, L. (2013, abril). Retos de accesibilidad en la formación virtual para personas con discapacidad motriz en las extremidades superiores. En $I V$ Congreso Internacional sobre Calidad y Accesibilidad de la Formación Virtual (CAFVIR 2013). Lisboa: Portugal.

Ley Orgánica 4/2007, de 12 de abril, por la que se modifica la Ley Orgánica 6/2001, de 21 de diciembre, de Universidades. Recuperado el 17 de octubre de 2014. www.boe.es/ buscar/doc.php?id-BOE-A-2007-7786.

Loy, B. y Batiste, L. (1998). Surfing the net: the three keys to universal access [online]. Recuperado el 14 de mayo de 2014. http://www.dinf.org/csun_98/csun98_011.htm.

Martínez, B.; Peguero, P.; Ezpeleta, J.; Falcó, J.; Lleida, E.; Mínguez, J. y Saz, O. (2007, octubre). Universidad y Educación Especial: Desarrollo y Resultados de la Colaboración entre el Centro Politécnico Superior y el Centro de Educación Especial «Alborada». En III Congreso Nacional sobre Universidad y Discapacidad. Zaragoza: España. 
UNA APROXIMACIÓN A LA REALIDAD DE LAS PLATAFORMAS VIRTUALES DE LAS UNIVERSIDADES ESPAÑOLAS: EL PRIMER RETO PARA UNA EDUCACIÓN PERSONALIZADA EN PERSONAS CON DISCAPACIDAD...

Ministerio de Trabajo y Asuntos Sociales (2007). Libro blanco sobre universidad y discapacidad. Madrid: Real Patronato sobre Discapacidad.

Miró, J. y Bernabeu, P. A. (s. f.). Accesibilidad de usuarios con discapacidad motora severa a un sitio web educativo. Recuperado el 12 de octubre de 2014. http://www.ufrgs.br/ niee/eventos/RIBIE/2006/ponencias/art048.pdf.

OMS (1999). CIDDM-2: Clasificación Internacional del Funcionamiento y la Discapacidad. Borrador Beta-2, Versión Completa. Ginebra: Organización Mundial de la Salud.

Oms (2011). Discapacidades. Recuperado el 18 de octubre de 2014. http://www.who.int/ topics/disabilities/es/.

Oms (2014). Ceguera y discapacidad visual. Recuperado el 15 de mayo de 2014. http://www. who.int/mediacentre/factsheets/fs282/es/.

Organización Nacional de Ciegos Españoles (ONCE) (2013). Datos de afiliación de la ONCE. Recuperado el 15 de mayo de 2014. http://www.once.es/new/afiliacion/datos-estadisticos.

Peralta, A. (2010). Libro blanco sobre universidad y discapacidad. Madrid: Real Patronato sobre Discapacidad.

Porras, M. y Ribera, M. (2008, junio). Estudio de caso: Una Evaluación de la Accesibilidad Web Mediante wCAG y Observación de Usuarios Ciegos y con Restos de Visión. En $I X$ Congreso Internacional Interacción. Albacete: España. Recuperado el 15 de mayo de 2014. http://aipo.es/articulos/2/12.pdf.

Puzis, Y. (2012, octubre). An interface agent for non-visual, accessible web automation. En Adjunct proceedings of the 25th annual ACM symposium on User interface software and technology. Cambridge: USA. http://dx.doi.org/10.1145/2380296.2380319

Ribera, M.; Térmens, M. y Frías, A. (2009). La accesibilidad de las webs de las universidades españolas. Balance 2001-2006. Revista Española de Documentación Científica, 32 (3), 66-88.

http://dx.doi.org/10.3989/redc.2009.3.683

Rocha, R.; Cobo, Á. y Alonso, M. (2011). Administración electrónica en las universidades públicas españolas. Revista Española de Documentación Científica, 34 (4), 545-562. http://dx.doi.org/10.3989/redc.2011.4.845

Rodríguez, D. J.; Viera, J. G. y Castillo, J. (2006). Universidad y Accesibilidad. Situación en España. Revista Iberoamericana de Sistemas, Cibernética e Informática, 3 (2), 33-37.

Rodríguez, M. T. (2000, julio). Accesibilidad a la web de las personas con discapacidad visual. En I Congreso Nacional de Nuevas Tecnologías y Necesidades Educativas Especiales. Murcia: España.

Román, M.; Bernier, J. L. y Rojas, I. (2013, septiembre). Análisis de la Accesibilidad Web de las Universidades Españolas. En CEDI. Madrid: España.

Serrano, I. y Palomares, A. (2013). La accesibilidad en las TIC para los alumnos con discapacidad visual: Un reto para el profesorado. etic@net, 13 (1), 66-85.

Térmens, M.; Ribera, M. y Sulé, A. (2003). Nivel de accesibilidad de las sedes web de las universidades españolas. Revista Española de Documentación Científica, 26 (1), 19-37.

Theofanos, M. F. y Redish, J. C. (2003). Guidelines for accessible and usable web sites: Observing users who work with screen readers. Interactions, 10 (6), 38-51.

Toledo, P. (2001). La accesibilidad en las Web de las universidades andaluzas. Pixel-Bit: Revista de Medios y Educación, 17, 53-66.

Universidad de Málaga (2012). Enpathia: Accesibilidad informática para personas con discapacidad motora severa. Recuperado el 11 de mayo de 2014. http://www.uma.es/ 
UNA APROXIMACIÓN A LA REALIDAD DE LAS PLATAFORMAS VIRTUALES DE LAS UNIVERSIDADES ESPAÑOLAS: EL PRIMER RETO PARA UNA EDUCACIÓN PERSONALIZADA EN PERSONAS CON DISCAPACIDAD...

otri/noticias/exito-enpathia-accesibilidad-informatica-para-personas-con-discapacidadmotora-severa.

Vigo, M. y Harper, S. (2013, May). Evaluating accessibility-in-use. En Proceedings of the 2013 International Cross Disciplinary Conference on Web Accessibility (W4A). Rio de Janeiro: Brasil. http://dx.doi.org/10.1145/2461121.2461136

w3C (1999). Web Content Accesibility Guidelines (wCAG 1.0). w3C Recommendation 5 May 1999. Recuperado el 15 de mayo de 2014. http://www.w3.org/TR/WCAG10/.

w3C (2008). Web Content Accesibility Guidelines (wCAG 2.0). w3C Recommendation 11 December 2008. Recuperado el 15 de mayo de 2014. http://www.w3.org/TR/WCAG20/.

w3C (2012). Las Pautas de Accesibilidad al Contenido Web 2.0 del w3C aprobadas como Estándar Internacional ISO/IEC. Recuperado el 14 de mayo de 2014. http://www.w3c. es/Prensa/2012/nota121015_wcag2pas.

Webaim (2014). Considering the User Perspective: A Summary of Design Issues. Recuperado el 14 de mayo de 2014. http://webaim.org/articles/userperspective/.

Zhu, S.; Sato, D.; Takagi, H. y Asakaba, C. (2010). Sasayaki: an augmented voice-based web browsing experience. En Proceedings of the 12th international ACM SIGACCESS Conference on Computers and accessibility. New York: USA.

http://dx.doi.org/10.1145/1878803.1878870 